\title{
Captação de recursos via transferências voluntárias: um olhar para os municípios do Consórcio Intermunicipal da Região Oeste Metropolitana de São Paulo (Cioeste)
}

\author{
Merlyn Alvares Ambrosio Alvares \\ Universidade Federal de São Paulo (Unifesp) \\ Marcello Simão Branco \\ Universidade Federal de São Paulo (Unifesp)
}

Este estudo tem o objetivo de analisar a captação de recursos federais, via transferências voluntárias, realizada por municípios que compõem o Consórcio Público Intermunicipal da Região Oeste Metropolitana de São Paulo (Cioeste). Optou-se por contextualizar o federalismo no Brasil e as atribuições municipais a partir da Constituição Federal de 1988, após identificar o perfil socioeconômico dos municípios que compõem o Cioeste, para então aprofundar a análise da captação de recursos, utilizando o método de estatística descritiva e análise de cluster. De maneira geral, observa-se que a escolha pelo consorciamento é justificada, uma vez que é uma alternativa cada vez mais buscada por municípios brasileiros para estimular sistemas cooperativos e o desenvolvimento regional. No entanto, alguns municípios do Cioeste apresentam perfil socioeconômico e comportamento de captação de recursos distintos, o que requer maior atenção da instituição, a fim de melhorar a eficiência e o desempenho dos projetos em âmbito municipal e regional.

Palavras-chave: transferência de recursos, administração municipal, consórcio público

[Artigo recebido em 13 de janeiro de 2017. Aprovado em 21 de fevereiro de 2018.] 
Mecanismos de captación de recursos em el sistema federativo: un vistazo para los municipios del Consorcio Intermunicipal de la Región Oeste Metropolitana de San Pablo (Cioeste)

Este estudio tiene por objetivo analisar la captación de recursos federales, por medio de transferencias voluntarias, realizada por municipios que componen el Consorcio Público Intermunicipal de la Región Oeste Metropolitana de San Pablo (Cioeste). Se optó por contextualizar el federalismo en Brasil y las atribuciones municipales a partir de la Constitución Federal de 1988, despúes de identificar el perfil socioeconómico de los municipios que componen el Cioeste, para profundizar el análisis de la captación de recursos, utilizando el método de estadística descriptiva y análisis de cluster. En general, se observa que la opción por el consorcio se justifica dado que es una alternativa cada vez mas buscada por municipios brasileños para estimular sistemas cooperativos y el desarrollo regional. Sin embargo, algunos municipios del Cioeste presentan perfil socioeconómico y comportamiento de captación de recursos distintos, lo que requiere mayor atención de la institución, con el objetivo de mejorar la eficiencia y desempeño de los proyectos en ámbito municipal y regional.

Palabras clave: transferencia de recursos, administración municipal, consorcio público

\section{Fundraising by way of voluntary transfers: a look at the municipalities of the Intermunicipal Consortium of the West Metropolitan Region of São Paulo (Cioeste)}

This study aims to analyze fundraising of federal resources through voluntary transfers carried out by municipalities that make up the Public Intermunicipal Consortium of the Metropolitan West Region of São Paulo (Cioeste). It was decided to first contextualize federalism in Brazil and the municipal attributions from the Federal Constitution of 1988, after identifying the socioeconomic profile of the municipalities that compose the Cioeste, to then deepen the analysis of the fundraising, using for that the method of descriptive statistics and Decluster analysis. In general, it is observed that the option of consortium is justified, since it is an alternative increasingly sought by Brazilian municipalities to stimulate cooperative systems and regional development. However, some municipalities of the Cioeste have a different socioeconomic profile and fundraising behavior, which requires greater attention from the institution in order to improve the efficiency and performance of the projects at the municipal and regional level.

Keywords: transfer of resources, municipal administration, public consortium 


\section{Introdução}

Conciliar as demandas da população por intervenções públicas e os recursos disponíveis para satisfazê-las está, conforme apontam especialistas, entre os grandes desafios da administração pública atual (GoverNo DE MINAS GERAIS, 2016).

Para tanto, a captação de recursos é essencial para garantir a execução de políticas públicas em âmbito local, sendo que há diversos instrumentos legais de planejamento para a realização de transferências de recursos obrigatórias e voluntárias entre os entes federados.

O presente artigo se concentra nas transferências voluntárias realizadas pela União a municípios, tendo por objetivo analisar a captação de recursos federais, via transferências voluntárias, realizada por municípios que compõem o Consórcio Público Intermunicipal da Região Oeste Metropolitana de São Paulo (Cioeste).

Segund o o Portal da Transparência, transferências voluntárias são: "Instrumentos celebrados pelos órgãos e entidades da Administração Pública Federal com órgãos ou entidades públicas (administração estadual, distrital, municipal) ou privadas sem fins lucrativos para a execução de programas, projetos e atividades de interesse recíproco" (PORTAL DA TRANSPARÊNCIA, 2016).

As transferências podem acontecer por programas contínuos e editais de chamamento, como também por meio das conhecidas emendas parlamentares, mecanismos que o Congresso Nacional possui para participar no orçamento anual. Por meio das emendas, os parlamentares procuram aperfeiçoar a proposta orçamentária encaminhada pelo Poder Executivo, visando a uma melhor alocação dos recursos públicos.

Os dois instrumentos de operacionalização das transferências voluntárias são o convênio e o contrato de repasse, sendo que o convênio é firmado diretamente entre as partes, e o contrato de repasse é firmado com os interessados e uma instituição interveniente.

Para seguir os princípios constitucionais e da legislação referenciada, as transferências voluntárias são controladas, auditadas e divulgadas por meio de um sistema aberto a todo cidadão, o Portal de Convênios do Governo Federal (Siconv).

O artigo utiliza o método de estatística descritiva e análise de cluster, a fim de verificar suas semelhanças, diferenças e os desafios no fornecimento de serviços e bens públicos em relação à escassez de recursos.

Após esta introdução, são apresentados os métodos de pesquisa, para então tratar do referencial teórico, que faz uma breve abordagem sobre o federalismo no Brasil e as atribuições municipais após a Constituição de 1988, bem como sobre a estrutura 
das transferências de recursos entre os entes federados, a ser analisada a partir da formação do consórcio Cioeste com o perfil socioeconômico dos municípios que o compõem, trazendo elementos para a análise da captação de recursos e classificação dos municípios, gerando assim as considerações finais do artigo.

\section{Método da pesquisa}

Inicialmente optou-se por contextualizar o federalismo no Brasil e as atribuições municipais após a Constituição de 1988 e sua estrutura de transferências de recursos entre os entes federados, para depois analisar o perfil socioeconômico dos municípios estudados, com o Produto Interno Bruto (PIB), PIB per capita, densidade demográfica, população, índice de desenvolvimento humano municipal (IDHM), receita corrente, receita corrente per capita, renda per capita, dados estes coletados no portal do IBGE e no portal Meu Município, com base no censo demográfico de 2010 e nas receitas correntes de 2014 e 2015, para compreender o contexto em que esses municípios atuam no Consórcio Público Intermunicipal da Região Oeste Metropolitana de São Paulo (Cioeste).

Para análise da captação de recursos federais desses municípios, foi utilizado o método de estatística descritiva sobre o conjunto de dados coletados e sistematizados do Portal da Transparência do Governo Federal. E, por último, para identificar e classificar a tendência dos municípios de acordo com suas características de similaridades ou dissimilaridades, foi utilizada a análise de cluster.

\section{Referencial teórico: federalismo e as atribuições dos municípios a partir da Constituição de 1988}

O federalismo, segundo Branco (2007, p. 109), "é um sistema político com divisão de poder no interior de um território no qual seus membros [...] realizam um pacto por meio de uma Constituição". Cada um desses membros detém autonomia, mas possuem uma "ligação com um governo central que retém para si a soberania política do território como um todo" (BRANCO, 2007, p. 109).

O federalismo surge no Brasil após a instauração da República, em 1891, para amenizar as reivindicações regionais, que exigiam maior autonomia, e para manter o território nacional unido. No entanto, segundo Branco (2007, p. 118), o federalismo no Brasil "sofre influências dos momentos de autoritarismo e democracia vividos pelo país" ao longo do século 20.

Um "novo federalismo" surge no Brasil após a promulgação da Constituição Federal de 1988, que, por influências de governadores e líderes regionais, torna-se uma das constituições mais descentralizadas do mundo. Isso garante aos estados 
e sobretudo aos municípios "amplas parcelas de impostos" e a "descentralização administrativa" (BRANCO, 2007, p. 123; AlMEIDA, 2001, p. 32).

Corroborando com essa visão, Franzese (2010) aponta que:

A Constituição Federal de 1988 trouxe muitas inovações no que se refere ao desenho federativo brasileiro e às competências de cada esfera de governo na promoção de políticas sociais. Dentre as principais características do novo desenho institucional, a literatura nacional dos anos 1990 destacou a forte diretriz de descentralização em favor dos governos municipais, que consolidava a imagem de que o Brasil tornara-se uma das federações mais descentralizadas do mundo (SouzA, 1996). A esse novo contexto somouse uma conjuntura de crise fiscal federal e de implementação da chamada "primeira onda" de reformas de Estado, com o objetivo de redução do tamanho do Estado e com uma agenda de corte de gastos, mesmo que à custa da diminuição de atuação do governo federal nas políticas públicas (FRANZESE, 2010, p. 14).

As políticas sociais destacam os problemas da coordenação federativa. Essas questões surgem a partir das garantias constitucionais uniformes e da preservação das diversidades regionais (OBINGER et al., 2005 apud MACHADO; PALOTTI, 2015, p. 62). Segundo Machado e Palotti (2015):

Na medida da variação do grau de interdependência entre escolhas dos entes governamentais, nas diferentes políticas públicas, coloca-se a necessidade de coordenação entre suas ações, a fim de assegurar resultados coletivos minimamente consistentes. Tal coordenação pode resultar de constrangimentos legais, incentivos financeiros ou parcerias que produzam convergência na direção de tais escolhas, seja no sentido de realizar objetivos fixados no plano nacional, seja de eliminar irracionalidades decorrentes da superposição ou da inexistência de iniciativas (MACHADO; PALOTTI, 2015, p. 62).

O federalismo democrático brasileiro entra em uma segunda fase a partir de 1994 com a adoção do Plano Real, passando "a conviver com mecanismos centralizadores", principalmente do ponto de vista da área fiscal, que adota "uma política de impostos não compartilhados com os estados e criação de outros, o que condiciona os gastos dos estados, pressionando a investirem em serviços que antes não cobriam" (BRANCO, 2007, p. 123).

Segundo Franzese (2010), diante da municipalização das políticas públicas, o Governo Federal iniciou um processo de padronização nacional dessas políticas: 
A partir da segunda metade da década de 1990, o governo federal - em boa medida recuperado da crise anterior, com o fim da inflação passou a implementar uma série de ações, com o objetivo de nacionalizar padrões de políticas públicas e aumentar a coordenação entre os entes federativos. A principal estratégia adotada foi a criação de condições atrativas, principalmente por meio de transferências intergovernamentais, para que estados e municípios passassem a aderir às diretrizes nacionais na implementação dessas políticas (FRANZESE, 2010, p. 14).

Corroborando essa teoria, segundo Arretche (2004, 2009, 2010) e Melo (2005), a partir dos anos 1990, há um movimento de recentralização do federalismo brasileiro, em que o Governo Federal passa a coordenar as políticas públicas, apesar de preservar os espaços de autonomia dos estados e municípios (ARRETCHE, 2004, 2009, 2010; Melo, 2005, apud MACHAdo; PalotTI, 2015, p. 64).

No entanto, Machado e Palotti (2015) indagam se o compartilhamento constitucional de responsabilidades do federalismo brasileiro estaria avançando para um padrão centralizado ou para um padrão cooperativo. Sendo

o compartilhamento constitucional de responsabilidades um atributo compatível, ao mesmo tempo, com um padrão cooperativo ou com um padrão centralizado, parece-nos relevante analisar em que medida o federalismo brasileiro estaria avançando em uma ou outra direção, em especial em áreas governamentais em que tal compartilhamento se apresenta. Seria seu padrão dominante mais próximo dos traços típicos do federalismo cooperativo em que se observa uma "ação conjunta entre instâncias de governo, nas quais as unidades subnacionais guardam significativa autonomia decisória e capacidade própria de financiamento" (ALMEIDA, 2000, p. 13-14)? Ou poderíamos afirmar com alguma segurança que nosso federalismo é centralizado? (MACHADO; PALOTTI, 2015, p. 64).

Nesse contexto, esses autores analisam os constrangimentos legais e constitucionais mais relevantes para atuação dos governos estaduais e municipais:

Nos constrangimentos diretos o próprio texto constitucional ou leis regulamentares ou complementares definem limites ou obrigações que diminuem a margem de escolha de estados e municípios ao atuarem nas políticas sociais. Estes incluem a vinculação do gasto de receitas orçamentárias próprias a determinada área de governo, como ocorre na educação e na saúde (ARRETCHE, 2004); critérios para uso desses recursos vinculados ou, mesmo, restrições para gastos com pessoal e endividamento, entre outros (MACHADO; PALOTTI, 2015, p. 66). 
Ainda segundo eles, tendo em vista a limitação financeira dos entes subnacionais, as transferências financeiras condicionadas são instrumentos que garantem as prioridades e a agenda do Governo Federal, sem necessidade de coerção, pois, no momento em que os governos estaduais e municipais aderem a esses programas e acessam esses recursos, ficam necessariamente condicionados às regras do Executivo federal:

As transferências intergovernamentais condicionadas agregam novos elementos à discussão sobre o caráter do federalismo brasileiro. Detentor de recursos financeiros e poder normativo, além de burocracia especializada e recursos informacionais diferenciados, o Executivo federal as adotou como estratégia privilegiada para indução da agenda social dos governos subnacionais, que, sob significativas restrições fiscais, têm aderido aos programas federais. Tal cenário converge para o federalismo centralizado, nos termos definidos pela $\mathrm{ACIR}^{1}$ (1981), em que governos subnacionais se comportam como agents da União; mas também, supostamente, contempla atributos do federalismo cooperativo: a configuração de arenas intergovernamentais de caráter federativo para pactuação em torno de programas, projetos e distribuição de responsabilidades e recursos entre as três esferas de governo (MACHADO; PALOTTI, 2015, p. 69).

Para esses autores, a disseminação de consórcios públicos poderia proporcionar um sistema federativo mais cooperativo em que:

A disseminação de associações voluntárias para produção e distribuição de valores entre entes governamentais poderia conferir ao sistema federativo brasileiro um caráter, de fato, cooperativo, em contraste com a própria definição proposta pela ACIR, pautada pelo compartilhamento formal de responsabilidades por uma área de governo. Assim, (...) a presença ampla e autossustentada de consórcios públicos poderia sugerir sua complementação por um componente horizontal. Mas é ainda impreciso constatar se as evidências disponíveis sobre consórcios intergovernamentais fornecem indicações nesta direção ou se, ao contrário, sugerem uma propagação ainda instável e dependente de iniciativas de indução por agentes "externos" ou, ainda, de contextos setoriais específicos (MACHADO; PALOTTI, 2015, p. 73).

Segundo Marta Farah (2001), existem várias experiências de consórcios intermunicipais, o que gera uma articulação entre esses governos, em que "se reúnem em torno de objetivos comuns, procurando formular, de forma conjunta,

\footnotetext{
${ }^{1}$ Advisory Commission on Intergovernmental Relations.
} 
planos para o enfrentamento de questões que ultrapassam a capacidade de resolução de um município isolado" (FARAH, 2001, p. 135).

No entanto, ainda segundo Machado e Palotti (2015, p. 76-77), embora haja um número expressivo de arranjos cooperativos entre governos locais no federalismo brasileiro, eles não possuem "um caráter autossustentado na estabilização de suas formas institucionais". Ao contrário, "a dependência do Executivo federal em relação à iniciativa de regulamentação gerou dinâmicas setoriais distintas que envolvem movimentos de expansão e retração, bem como a subordinação a agentes externos". E concluem que, "assim como no caso das transferências financeiras condicionadas, a dinâmica das parcerias entre municípios, como os consórcios, termina por revelar fortes traços de dependência de iniciativas de outras esferas de governo" (MACHADO; PALOTTI, 2015, p. 77).

\section{A estrutura das transferências de recursos entre os entes}

O orçamento público no Brasil é disciplinado por diferentes instrumentos de planejamento, estabelecidos pela Lei de Finanças Públicas (Lei no 4.320/1964), pela Constituição Federal (CF/1988), pela Lei de Licitações e Contratos (Lei no 8.666/1993), que institui normas para licitações e contratos da Administração Pública, e pela Lei de Responsabilidade Fiscal (LRF - Lei Complementar no 101/2000).

Além desses mecanismos, as transferências a municípios são regulamentadas pelo Decreto no 6.170, de 25 de julho de 2007; pela Portaria Interministerial no 127, de 29 de maio de 2008; e pela Portaria Interministerial no 507, de 28 de novembro de 2011, que regula os convênios, os contratos de repasse e os termos de cooperação celebrados entre os entes federados (AlVARES et al., 2016; SILVA; MEDEIROS, 2015).

Esses instrumentos estabelecem as diretrizes de transferências de recursos entre os entes federados, que, segundo o Portal da Transparência (2016), podem ser classificadas como:

\section{Transferências fundo a fundo}

Caracterizam-se pelo repasse, por meio da descentralização, de recursos diretamente de fundos da esfera federal para fundos da esfera estadual, municipal e do Distrito Federal, dispensando a celebração de convênios. As transferências fundo a fundo são utilizadas nas áreas de assistência social e de saúde (PORTAL DA TRANSPARÊNCIA, 2016). 


\section{Transferências legais}

São as parcelas das receitas federais arrecadadas pela União, repassadas aos estados, ao Distrito Federal e aos municípios, previstas em leis específicas. Essas leis determinam a forma de habilitação, a transferência, a aplicação dos recursos e como deverá ocorrer a respectiva prestação de contas.

Dentre as principais transferências da União para os estados, o DF e os municípios previstas em leis, destacam-se: o Programa Nacional de Alimentação Escolar (PNAE), o Programa Nacional de Apoio ao Transporte do Escolar (PNATE), o Programa Dinheiro Direto na Escola (PDDE), o Programa de Apoio aos Sistemas de Ensino para Atendimento à Educação de Jovens e Adultos, entre outros (PORTAL DA TRANSPARÊNCIA, 2016).

\section{Transferências constitucionais}

São transferências, previstas na Constituição Federal, de parcelas das receitas federais arrecadadas pela União e que devem ser repassadas aos estados, ao Distrito Federal e aos municípios. O objetivo do repasse é amenizar as desigualdades regionais e promover o equilíbrio socioeconômico entre estados e municípios.

Dentre as principais transferências da União para os estados, o DF e os municípios previstas na Constituição, destacam-se: o Fundo de Participação dos Estados e do Distrito Federal (FPE); o Fundo de Participação dos Municípios (FPM); o Fundo de Compensação pela Exportação de Produtos Industrializados (FPEX); o Fundo de Manutenção e de Desenvolvimento do Ensino Fundamental e de Valorização do Magistério (Fundef), substituído pelo Fundo de Manutenção e Desenvolvimento da Educação Básica e de Valorização dos Profissionais da Educação (Fundeb), criado pela Emenda Constitucional no56/2006; e o Imposto sobre a Propriedade Territorial Rural (ITR) (PORTAL DA TRANSPARÊNCIA, 2016).

\section{Transferências destinadas ao Sistema Único de Saúde (SUS)}

São transferências tratadas separadamente por conta da relevância do assunto, por meio da celebração de convênios, de contratos de repasses e, principalmente, de transferências fundo a fundo.

O SUS compreende todas as ações e serviços de saúde estatais das esferas federal, estadual, municipal e distrital, bem como os serviços privados de saúde contratados ou conveniados. Os valores são depositados diretamente do Fundo Nacional de Saúde aos fundos de saúde estaduais, municipais e do Distrito Federal. 
Os depósitos são feitos em contas individualizadas, isto é, específicas dos fundos (PorTAl dA TRANSPARÊNCIA, 2016).

\section{Transferências voluntárias}

São os recursos financeiros repassados pela União aos estados, Distrito Federal e municípios em decorrência da celebração de convênios, acordos, ajustes ou outros instrumentos similares, cuja finalidade é a realização de obras e/ou serviços de interesse comum. A transferência voluntária é a entrega de recursos a outro ente da Federação, a título de cooperação, auxílio ou assistência financeira, que não decorra de determinação constitucional, legal ou os destinados ao Sistema Único de Saúde (SUS) (PorTAL DA TRANSPARÊNCIA, 2016).

O Governo Federal utiliza as transferências como forma de incentivar a execução de projetos que ele não pode executar diretamente por conta da distribuição de atribuições entre os entes da Federação, como obras ou serviços de interesse comum.

Os principais instrumentos de operacionalização das transferências são o convênio e o contrato de repasse. O convênio é firmado diretamente entre órgãos da administração pública, e o contrato de repasse é estabelecido entre os interessados e uma instituição interveniente.

São exemplos de intervenientes a Caixa Econômica Federal e o Banco do Brasil, que, em alguns casos, atuam também como apoio técnico à execução dos projetos no âmbito municipal (Alvares et al., 2016; SILVA; MedeIROS, 2015).

Frente às inúmeras dificuldades de gestão, muitos municípios passaram a criar estruturas responsivas às organizações federais, como o caso de secretarias e departamentos específicos para tratar de convênios, consultorias e capacitações (Alvares et al., 2016; Silva; MedeiRos, 2015). Segundo a representante da Caixa Econômica Federal do município de Osasco/SP,

Os municípios que se estruturam tanto administrativamente, quanto tecnicamente para atuar com transferências voluntárias conseguem dar o foco necessário para que as operações tenham um ciclo de vida saudável e breve. Contudo, aqueles que não possuem condições para esse tipo de estruturação, muitas vezes acabam por perder os recursos federais (Entrevista concedida em 14.05.2015 apud SILVA; MEDEIROS, 2015).

Reforçando a análise, o Especialista em Políticas Públicas e Gestão Governamental do Ministério das Cidades aponta que:

É possível perceber que aqueles entes subnacionais que possuem uma maior capacidade para a apresentação de projetos melhor elaborados, bem 
como apresentam condições técnicas e operacionais mais desenvolvidas, para a execução das políticas públicas em seu território, apresentam uma utilização de recursos públicos de maneira mais eficiente (Entrevista concedida em 15.05.2015 apud Silva; MedeIROS, 2015).

Segundo Ferreira, o planejamento é uma ação contínua e possui três fases: preparação do plano, acompanhamento da ação e revisão crítica dos resultados. Nesse sentido, não basta preparar e organizar as ações. Para alcançar os objetivos propostos é fundamental acompanhar e revisar todas as ações, resolvendo sem improvisação os problemas e circunstâncias inesperadas que surgem (FERREIRA, 1979).

Corroborando essas análises, os municípios brasileiros passaram a identificar a necessidade de organizar e melhor operacionalizar a gestão pública a fim de tornar eficiente o desenvolvimento dos projetos em âmbito municipal, uma das razões para a criação de equipes específicas para lidar com o planejamento e gestão do município, muitas vezes identificadas como escritórios de projetos.

Um escritório de projetos "é um pequeno grupo de pessoas que têm relacionamento direto com todos os projetos, seja prestando consultoria e treinamento, seja efetuando auditoria e acompanhamento de desempenho" (PRADO, 2000).

É possível observar a crescente importância dos escritórios de projetos a partir da década de 1990 no Brasil, quando ganha força o movimento da Nova Administração Pública, que se caracteriza por transformar as práticas cultivadas no âmbito da administração de empresas, como modelo de gestão orientada para resultado, planejamento estratégico, gestão de processo, foco no cliente, profissionalização da gestão pública, entre outros, em referencial para o setor público (PACHECO, 2004; SiLVA; MEDEIROS, 2015).

\section{O Consórcio Intermunicipal da Região Oeste Metropolitana de São Paulo (Cioeste) e o perfil socioeconômico dos municípios que o compõem}

Dentre as alternativas possíveis adotadas por diversos municípios para ampliar os recursos por eles captados, destaca-se a criação de consórcios públicos intermunicipais. Unidos, os municípios têm maior força política para captação de recursos e, somado a isso, o Manual de Obtenção de Recursos Federais para Municípios (SEnAdo Federal, 2016) destaca que as soluções consorciadas são priorizadas para obtenção de recursos, o que favorece não apenas a captação de recursos, como também impactam positivamente um maior número de pessoas. Segundo Prates (2010): 
[...] o tema da organização e administração territorial se encontra na agenda política em todos os países do mundo, sobretudo frente ao crescente processo de globalização ocorrido nas últimas décadas. Nesse quadro as municipalidades se colocam na ponta de frente desse processo e, em que pese os limites de governança em suas territorialidades, os consórcios se constituem como políticas públicas de grande relevância para o desenvolvimento local (PRATEs, 2010, p. 28).

Conforme Caldas (2007, apud PRATES, 2010), algumas vertentes definem os Consórcios Públicos (CPs): 1) constituem em uma ação conjunta com vistas à solução de problemas comuns; 2) uma instituição que reúne diversos municípios para realizar ações conjuntas com o objetivo de potencializar a utilização dos recursos físicos e financeiros existentes; 3) associação criada entre os mesmos entes de governo para a execução de ações e/ou serviços públicos de interesse comum; e 4) são acordos pactuados entre diferentes entes, porém da mesma "espécie", com o objetivo de executar ações de interesse comum, utilizando os recursos de que cada membro dispõe. Prates (2010), aponta que:

[...] o fato é que os CPs se constituem na idéia de "juntar" forças para a realização de objetivos que cada ente pertencente ao consórcio isoladamente não teria condições de sanar, dada a sua fragilidade financeira ou de recursos humanos. Isso não necessariamente quer dizer uma incapacidade municipal, por exemplo, mas antes uma tentativa de se criar escalas físicas e financeiras a fim de realizar investimentos a um custo muito menor para cada município participante do consórcio (PRATES, 2010, p. 08).

A fim de promover o desenvolvimento sustentável da região e amparados pela Lei no 11.107, de 06 de abril de 2005, conhecida como a Lei dos Consórcios Públicos, que permite a criação de uma entidade de cooperação, capaz de prestar serviços nas diferentes áreas da gestão municipal, oito municípios assinaram o Protocolo de Intenções e criaram o Consórcio Público Intermunicipal da Região Oeste Metropolitana de São Paulo (Cioeste), através da Lei no 4611, em 12 de novembro de 2013.

O Cioeste é composto pelos municípios de Osasco, Barueri, Carapicuíba, Itapevi, Jandira, Pirapora do Bom Jesus, Santana de Parnaíba e Cotia. Estão localizados na Região Metropolitana de São Paulo e, segundo o censo realizado em 2010, somam um total de 1.911.968 habitantes e o Produto Interno Bruto de aproximadamente $\mathrm{R} \$ 100$ bilhões.

São finalidades específicas do Cioeste atuar, por meio de ações regionais, como gestor, articulador, planejador ou executor e fiscalizador, nas seguintes 
áreas de interesse: 1) desenvolvimento econômico regional; 2) infraestrutura; 3) desenvolvimento urbano; 4) saúde; 5) educação, cultura e esportes; 6) assistência, inclusão social e direitos humanos; 7) segurança pública; 8) gestão ambiental; e 9) fortalecimento institucional (Lei no 4611, de 12 de novembro de 2013).

De acordo com Jorge Lapas, prefeito de Osasco na gestão 2013-2016 e expresidente do Cioeste:

Esse é o diferencial da nossa região, o Cioeste reúne lideranças em prol de algo maior, deixando de lado as siglas partidárias. Queremos ampliar a atuação, abrindo espaço para o Legislativo e sociedade discutirem projetos e trabalhar de forma unificada para ganhar força política em prol da região. A ideia é ampliar a participação com o apoio das câmaras, trabalhadores e entidades patronais que promovem o diálogo com a sociedade (COTIA AGORA, 2015).

Corroborando essa visão, em setembro de 2015 o Cioeste promoveu, em parceria com o Ministério das Cidades e a Caixa Econômica Federal, instituição interveniente nos contratos de repasse nesses municípios, o Programa de Formação de Projetos Urbanos, no âmbito do Programa Nacional de Capacitação das Cidades, com o objetivo de aprimorar o trabalho das equipes municipais por meio de um conjunto de informações necessárias para estruturação e apresentação de projetos vinculados às ações apoiadas pelo Ministério das Cidades.

O programa foi dividido em quatro módulos de projetos: 1) diagnóstico sobre o desenvolvimento urbano nos municípios brasileiros; e a necessidade de concepção e implementação de projetos; 2) elementos básicos para a concepção e implementação de projetos; 3) estruturação de propostas de projetos; e 4) elementos a observar na leitura dos manuais de acesso aos recursos, módulo esse dividido em quatro temáticas: saneamento, habitação, mobilidade urbana e regularização fundiária.

O Quadro 1 apresenta o perfil socioeconômico dos municípios estudados, com o produto interno bruto (PIB), PIB per capita, densidade demográfica, população, índice de desenvolvimento humano municipal (IDHM), receita corrente, receita corrente per capita, renda per capita, dados esses coletados no portal do IBGE e no portal Meu Município, com base no censo demográfico de 2010 e nas receitas correntes de 2014 e 2015.

Com esses dados é possível compreender o contexto em que esses municípios atuam no Consórcio Público Intermunicipal da Região Oeste Metropolitana de São Paulo (Cioeste). 
Quadro 1 - Perfil socioeconômico dos municípios que compõem o Cioeste

\begin{tabular}{|l|c|c|c|c|c|c|c|c|c|}
\hline & Popu- & $\begin{array}{c}\text { Densi- } \\
\text { dade } \\
\text { demo- } \\
\text { lação } \\
\text { (Censo } \\
\text {-gráfica } \\
\text { habi- } \\
\text { tantes/ } \\
\text { kmº }\end{array}$ & $\begin{array}{c}\text { IDHM } \\
2010\end{array}$ & $\begin{array}{c}\text { Renda } \\
\text { per } \\
\text { capita } \\
\text { (2010) }\end{array}$ & $\begin{array}{c}\text { \% po- } \\
\text { breza } \\
\text { (censo } \\
2010)\end{array}$ & PIB (2010) & $\begin{array}{c}\text { PIB per } \\
\text { capita } \\
(2010)\end{array}$ & $\begin{array}{c}\text { Receita } \\
\text { corrente (dados } \\
2014 / 2015)\end{array}$ & $\begin{array}{c}\text { Receita } \\
\text { corrente } \\
\text { per } \\
\text { capita }\end{array}$ \\
\hline Osasco & 666.469 & 10.418 & 0,776 & $1.003,40$ & 4,80 & $45.140 .281 .490,00$ & $67.730,50$ & $1.938 .465 .136,21$ & $2.908,56$ \\
\hline Carapicuíba & 369.908 & 10.870 & 0,749 & 712,78 & 6,12 & $3.043 .091 .840,00$ & $8.226,62$ & $379.242 .037,10$ & $1.025,23$ \\
\hline Barueri & 240.656 & 3.704 & 0,786 & $1.095,84$ & 5,65 & $31.893 .774 .605,00$ & $132.528,48$ & $2.256 .820 .313,78$ & $9.377,79$ \\
\hline Cotia & 201.023 & 623 & 0,78 & $1.085,66$ & 4,72 & $7.010 .809 .433,00$ & $34.875,66$ & $796.591 .027,42$ & $3.962,69$ \\
\hline Itapevi & 200.874 & 2.448 & 0,735 & 575,72 & 8,33 & $5.718 .597 .663,00$ & $28.468,58$ & $539.500 .803,96$ & $2.685,77$ \\
\hline Santana de & 108.875 & 608 & 0,814 & $1.858,69$ & 4,71 & $4.699 .134 .398,00$ & $43.160,82$ & $753.945 .524,19$ & $6.924,87$ \\
\hline Parnaíba & 108.436 & 6.373 & 0,76 & 792,33 & 4,4 & $2.177 .168 .468,00$ & $20.077,91$ & $247.278 .160,56$ & $2.280,41$ \\
\hline Jandira & 15.727 & 146 & 0,727 & 546,69 & 9,88 & $322.044 .116,00$ & $20.477,15$ & $53.065 .241,30$ & $3.374,15$ \\
\hline Pirapora do \\
Bom Jesus
\end{tabular}

Fonte: Elaboração própria, com base nos portais IBGE e Meu Município, 2016.

A partir da análise dos dados, o município de Osasco se destaca com uma população de 666.469 e o PIB de R\$ 45 bilhões. No entanto, Barueri se destaca no PIB per capita de $\mathrm{R} \$ 132.528,48$, na receita corrente, que é maior que a arrecadação de Osasco no valor de $\mathrm{R} \$ 2.256 .820 .313,78$ e na receita corrente per capita de $\mathrm{R} \$$ 9.377,79; enquanto Itapevi apresenta a segunda menor renda per capita e o segundo maior índice de pobreza.

Santana de Parnaíba possui o maior índice de desenvolvimento humano, 0,814, e a maior renda per capita, de $\mathrm{R} \$ 1.858,69$. Jandira apresenta a menor porcentagem de pobreza, 4,4; enquanto que Pirapora do Bom Jesus possui a menor população, com apenas 15.727 habitantes, e se destaca com o maior índice de pobreza, 9,88, menor IDHM, 0,727, e a menor renda per capita,, de apenas $\mathrm{R} \$ 546,69$ dentre os municípios do Cioeste.

O Quadro 2 apresenta a média, o desvio padrão e o erro da média da variável renda per capita. 
Quadro 2 - Estatísticas de uma amostra

\begin{tabular}{|l|l|l|l|l|}
\hline & N & Média & $\begin{array}{l}\text { Desvio } \\
\text { padrão }\end{array}$ & $\begin{array}{l}\text { Erro padrão da } \\
\text { média }\end{array}$ \\
\hline Renda per capita & 8 & 958,8888 & 422,82850 & 149,49245 \\
\hline
\end{tabular}

Fonte: Elaboração própria, com base nos portais IBGE e Meu Município, 2016, por meio do sistema SPSS.

O Quadro 3 apresenta a média, o desvio padrão e o erro da média da variável receita corrente per capita.

Quadro 3 - Estatísticas de uma amostra

\begin{tabular}{|l|l|l|l|l|}
\hline & N & Média & Desvio padrão & $\begin{array}{l}\text { Erro padrão da } \\
\text { média }\end{array}$ \\
\hline $\begin{array}{l}\text { Receita corrente } \\
\text { per capita }\end{array}$ & 8 & $4.067,3800$ & $2.739,38866$ & 968,52015 \\
\hline
\end{tabular}

Fonte: Elaboração própria, com base nos portais IBGE e Meu Município, 2016, por meio do sistema SPSS.

É possível analisar que, na média das variáveis apresentadas, há um elevado desvio padrão, isso porque alguns municípios se destacam em relação aos outros, o que pode representar alto índice de desigualdade econômica e social entre eles, entre outros elementos.

\section{Análise da captação de recursos e classificação dos municípios que compõem o Cioeste}

\section{Análise da captação de recursos}

Para a análise da captação de recursos dos oito municípios que compõem o Cioeste em âmbito federal, foi utilizado o método de estatística descritiva sobre o conjunto de dados coletados e sistematizados do Portal da Transparência do Governo Federal, conforme detalhamento no Quadro 4: 
Quadro 4 - Análise da captação de recursos por município

\begin{tabular}{|l|c|c|c|c|c|c|}
\hline Municípios & $\begin{array}{c}\text { Total de recursos } \\
\text { captados (de } \\
\text { 1996 a julho de } \\
\text { 2016) }\end{array}$ & $\begin{array}{c}\text { Recursos } \\
\text { captados } \\
\text { per capita }\end{array}$ & $\begin{array}{c}\text { Quantidade } \\
\text { de convênios } \\
\text { aprovados }\end{array}$ & $\begin{array}{c}\text { Em } \\
\text { execução }\end{array}$ & Finalizados & Cancelados \\
\hline Osasco & $367.127 .667,30$ & 550,85 & 193 & 29 & 142 & 22 \\
\hline Barueri & $3.101 .601,01$ & 12,89 & 11 & 1 & 9 & 1 \\
\hline Carapicuíba & $139.240 .819,77$ & 376,42 & 103 & 28 & 57 & 18 \\
\hline Itapevi & $116.583 .142,39$ & 580,38 & 109 & 8 & 80 & 21 \\
\hline $\begin{array}{l}\text { Santana de } \\
\text { Parnaíba }\end{array}$ & $16.399 .896,22$ & 150,63 & 53 & 3 & 38 & 12 \\
\hline Cotia & $25.412 .362,45$ & 126,42 & 53 & 18 & 28 & 7 \\
\hline Jandira & $40.281 .127,47$ & 371,47 & 98 & 74 & 12 & 12 \\
\hline $\begin{array}{l}\text { Pirapora } \\
\text { do Bom de } \\
\text { Jesus }\end{array}$ & $3.238 .045,13$ & 205,89 & 34 & 0 & 27 & 7 \\
\hline TOTAL & $711.384 .661,74$ & & 654 & 161 & 393 & 7 \\
\hline
\end{tabular}

Fonte: Elaboração própria, com base no Portal da Transparência, 2016, por meio do sistema SPSS.

Foram identificados um total de 654 projetos, sendo convênios ou contratos de

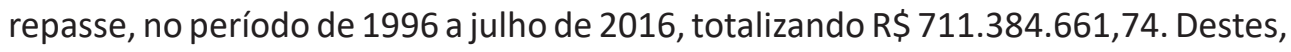
393 projetos já foram finalizados, 161 estão em execução e 100 foram cancelados.

O Gráfico 1 compara a captação de recursos federais por município nos últimos 20 anos. Pode-se observar que Barueri foi o município que menos captou recursos para execução de projetos, enquanto Osasco está em primeiro lugar, com uma captação de $\mathrm{R} \$ 367$ milhões. 
Gráfico 1 - A captação de recursos federais por município do Cioeste nos últimos 20 anos

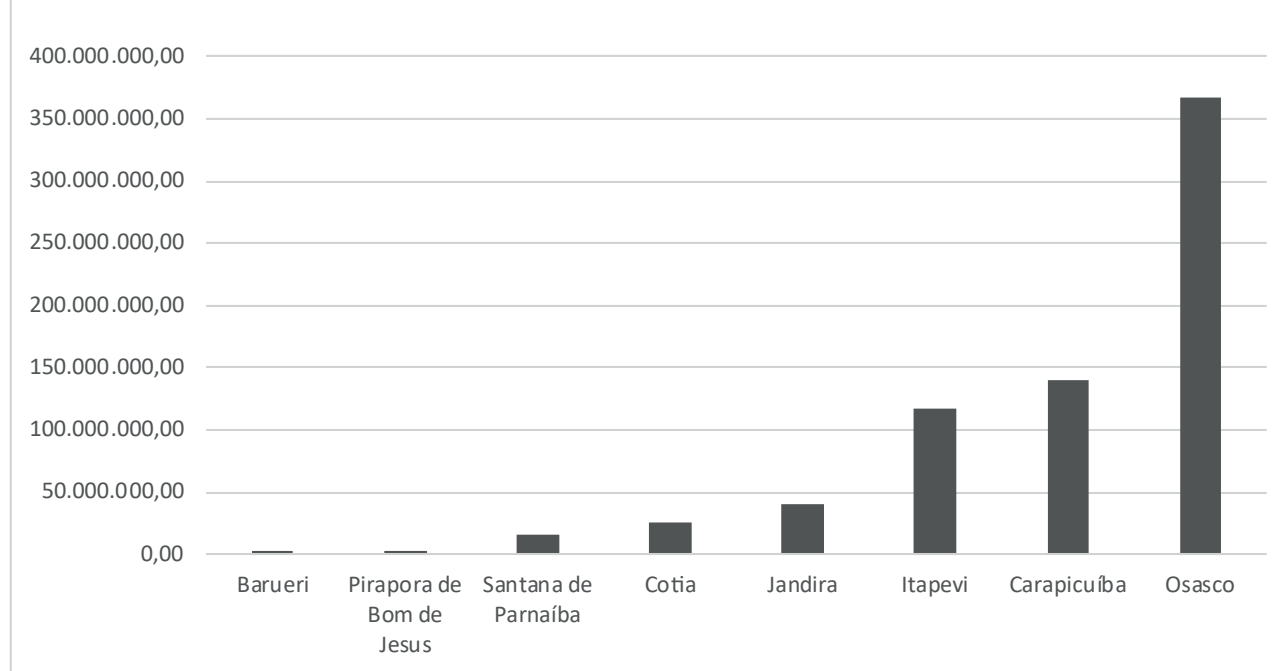

Fonte: Elaboração própria, com base no Portal da Transparência, 2016.

Vale ressaltar que os dados coletados não contemplam todos os valores captados no Governo Federal, como, por exemplo, recursos do PAC e fundo a fundo. Essas informações não estão disponíveis no Portal da Transparência do Governo Federal, e a única possibilidade de acesso à informação é por meio de senhas e perfis de gestores de projetos municipais, ou seja, há uma grande lacuna na informação disponibilizada.

Segundo o estudo realizado pela equipe do Departamento de Fortalecimento Institucional (Defi), da Secretaria de Planejamento e Gestão, da Prefeitura de Osasco (Alvares et al., 2016), a Prefeitura de Osasco captou, entre 1996 a agosto de 2015, mais de $R \$ 1$ bilhão de reais. Isso porque consideraram dados de projetos que não estão disponibilizados para qualquer cidadão.

São exemplos de portais de monitoramento restritos: Sistema Integrado de Monitoramento do Ministério da Educação (Simec), Sistema de Monitoramento de Obras do Ministério da Saúde (Sismob), o Sistema de Monitoramento do Programa de Aceleração do Crescimento (PAC), Portal da Caixa Econômica Federal, entre outros.

Outro problema encontrado na análise é que alguns projetos estão com valores diferentes do valor realmente pactuado com o Governo Federal. No entanto, essa observação também só foi possível obter porque tivemos acesso a fontes restritas 
de informações de um dos municípios estudados. Nesse sentido, optou-se por manter os valores coletados no Portal da Transparência do Governo Federal para não influenciar os dados da amostra.

O Quadro 5 apresenta as médias de recursos captados e de recursos captados per capita.

\section{Quadro 5 - Relatório}

\begin{tabular}{|l|l|l|}
\hline & Total recurso captado & $\begin{array}{l}\text { Recurso captado per } \\
\text { capita }\end{array}$ \\
\hline Média & $88.923 .082,7175$ & 296,9500 \\
N & 8 & 8 \\
Desvio padrão & $123.670 .796,19104$ & 205,74553 \\
\hline
\end{tabular}

Fonte: Elaboração própria, com base no Portal da Transparência, 2016, por meio do sistema SPSS.

Na média, a captação de recursos para execução de projetos nos municípios estudados ficou em R\$ 88 milhões e a captação per capita, ou seja, a soma dos valores arrecadados dividida pela soma da população, ficou em $\mathrm{R} \$ 296,95$.

No entanto, percebe-se elevado desvio padrão nas duas médias. Isso porque há uma distância considerável nos valores arrecadados entres os municípios, com maior destaque para o caso de Osasco, que captou aproximadamente $R \$ 367$ milhões, comparado com o município de Barueri, que captou apenas $\mathrm{R} \$ \mathbf{3}$ milhões.

O Quadro 6 apresenta o resumo de processamento dos casos, no qual, é importante destacar, não houve nenhum caso omisso.

Quadro 6-Resumo de processamento de casos

\begin{tabular}{|c|c|c|c|c|c|c|}
\hline \multirow{2}{*}{} & \multicolumn{3}{|c|}{ Casos } \\
\cline { 2 - 7 } & \multicolumn{2}{|c|}{ Válidos } & \multicolumn{2}{|c|}{ Omissos } & \multicolumn{2}{c|}{ Total } \\
\cline { 2 - 7 } & N & Porcentagem & N & Porcentagem & N & Porcentagem \\
\hline $\begin{array}{c}\text { Convenente } \\
\text { Status em } \\
\text { 19/07/2016 }\end{array}$ & 654 & $100,0 \%$ & 0 & $0,0 \%$ & 654 & $100,0 \%$ \\
\hline
\end{tabular}

Fonte: Elaboração própria, com base no Portal da Transparência, 2016, por meio do sistema SPSS.

O Quadro 7 apresenta a tabulação cruzada dos municípios, ou seja, a consolidação das informações da captação de recursos de 1996 até 19 de julho de 2016, apresentando o total de projetos captados, finalizados, em execução e cancelados. 
Quadro 7 - Tabulação cruzada convenente

\begin{tabular}{|c|c|c|c|c|c|}
\hline \multicolumn{6}{|c|}{ Contagem } \\
\hline & & \multicolumn{3}{|c|}{ Status em 19/07/2016 } & \multirow{2}{*}{ Total } \\
\hline & & Cancelado & Em execução & Finalizado & \\
\hline \multirow{8}{*}{ Convenente } & BARUERI & 1 & 1 & 9 & 11 \\
\hline & CARAPICUIBA & 18 & 28 & 57 & 103 \\
\hline & COTIA & 7 & 18 & 28 & 53 \\
\hline & ITAPEVI & 21 & 8 & 80 & 109 \\
\hline & JANDIRA & 12 & 12 & 74 & 98 \\
\hline & OSASCO & 22 & 29 & 142 & 193 \\
\hline & $\begin{array}{l}\text { PIRAPORA DO } \\
\text { BOM JESUS }\end{array}$ & 7 & 0 & 27 & 34 \\
\hline & $\begin{array}{l}\text { SANTANA DE } \\
\text { PARNAIBA }\end{array}$ & 12 & 3 & 38 & 53 \\
\hline \multicolumn{2}{|c|}{ Total } & 100 & 99 & 455 & 654 \\
\hline
\end{tabular}

Fonte: Elaboração própria, com base no Portal da Transparência, 2016, por meio do sistema SPSS.

Dos 654 projetos identificados, 455 projetos foram finalizados, o que representa 60,09\%; 99 projetos estão em execução, o que representa 24,62\%; e 100 projetos $(15,29 \%)$ foram cancelados, não sendo possível analisar as causas desses cancelamentos nas informações disponibilizadas por meio do Portal da Transparência do Governo Federal.

No entanto, algumas tendências podem explicar esse elevado índice de cancelamento de projetos, pois, segundo estudo realizado pela equipe do Defi (AlVARES et al., 2016) referente aos projetos captados pelo município de Osasco, no período de 1996 a agosto de 2015, muitos projetos foram aprovados sem dimensão orçamentária real, em terrenos inadequados e/ou com amarras judiciais, não cumprimento de prazos, entre outros.

\section{Classificação dos municípios por clusters de acordo com o perfil de captação de recursos}

O método utilizado para classificar os municípios de acordo com o perfil de captação de recursos federais foi o de cluster, que, segundo Guidini et al. (2008), "tem por objetivo encontrar as questões que estão mais correlacionadas, visando 
ao agrupamento, levando-se em consideração a semelhança entre as respostas das questões, como forma de verificar as características de gestão semelhantes".

A análise de cluster baseou-se nas características de total de recurso captado, recurso captado per capita, quantidade de projetos aprovados, quantidade de projetos em execução, quantidade de projetos finalizados e quantidade de projetos cancelados.

Os Quadros 8, 9, 10 e 11 apresentam o resultado obtido com a utilização da análise de cluster e associam os municípios de acordo com suas características.

\section{Quadro 8 - Centros do cluster iniciais}

\begin{tabular}{|c|c|c|c|}
\hline & \multicolumn{3}{|l|}{ Cluster } \\
\hline & 1 & 2 & 3 \\
\hline Total recurso captado & $367.127 .667,30$ & 3.101.601,01 & $139.240 .819,77$ \\
\hline Recurso captado per capita & 550,63 & 12,88 & 376,75 \\
\hline Quantidade projetos aprovados & 193 & 11 & 103 \\
\hline Em execução & 29 & 1 & 28 \\
\hline Finalizado & 142 & 9 & 57 \\
\hline Cancelado & 22 & 1 & 18 \\
\hline
\end{tabular}

Fonte: Elaboração própria, com base no Portal da Transparência, 2016, por meio do sistema SPSS.

\section{Quadro 9 - Associação de cluster}

\begin{tabular}{|l|l|l|l|}
\hline $\begin{array}{l}\text { Número do } \\
\text { caso }\end{array}$ & Município & Cluster & Distância \\
\hline 1 & Osasco & 1 &, 000 \\
\hline 2 & Barueri & 2 & $14.585 .005,447$ \\
\hline 3 & Carapicuíba & 3 & $11.328 .838,690$ \\
\hline 4 & Itapevi & 3 & $11.328 .838,690$ \\
\hline 5 & Santana de Parnaíba & 2 & $1.286 .710,236$ \\
\hline 6 & Cotia & 2 & $7.725 .755,994$ \\
\hline 7 & Jandira & 2 & $22.594 .521,015$ \\
\hline 8 & Pirapora do Bom Jesus & 2 & $14.448 .561,326$ \\
\hline
\end{tabular}

Fonte: Elaboração própria, com base no Portal da Transparência, 2016, por meio do sistema SPSS. 
Quadro 10 - Centros do cluster finais

\begin{tabular}{|l|c|c|c|}
\hline \multirow{2}{*}{} & \multicolumn{3}{|c|}{ Cluster } \\
\cline { 2 - 4 } & $\mathbf{1}$ & $\mathbf{2}$ & $\mathbf{3}$ \\
\hline Total recurso captado & $367.127 .667,30$ & $17.686 .606,46$ & $127.911 .981,08$ \\
\hline Recurso captado per capita & 550,63 & 173,51 & 478,72 \\
\hline Quantidade projetos aprovados & 193 & 50 & 106 \\
\hline Em Execução & 29 & 19 & 18 \\
\hline Finalizado & 142 & 23 & 69 \\
\hline Cancelado & 22 & 8 & 20 \\
\hline
\end{tabular}

Fonte: Elaboração própria, com base no Portal da Transparência, 2016, por meio do sistema SPSS.

Quadro 11 - Distâncias entre centros do cluster finais

\begin{tabular}{|c|c|c|c|}
\hline Cluster & $\mathbf{1}$ & $\mathbf{2}$ & $\mathbf{3}$ \\
\hline $\mathbf{1}$ & & $349.441 .060,844$ & $239.215 .686,220$ \\
\hline $\mathbf{2}$ & $349.441 .060,844$ & & $110.225 .374,624$ \\
\hline $\mathbf{3}$ & $239.215 .686,220$ & $110.225 .374,624$ & \\
\hline
\end{tabular}

Fonte: Elaboração própria, com base no Portal da Transparência, 2016, por meio do sistema SPSS.

Ao distribuir os oito municípios analisados por essas características em três grupos clusterizados, observa-se que o município de Osasco, por si só, compõe o cluster 1. Isso decorre de suas características de possuir valores de total de recurso captado, quantidade de projetos aprovados e quantidade de projetos finalizados muito superiores aos demais municípios. Ou seja, Osasco não apresenta nenhuma similaridade com os demais municípios do Cioeste no que se refere à captação de recursos federais.

Já o cluster 2, composto pelos municípios de Barueri, Cotia, Jandira, Pirapora do Bom Jesus e Santana de Parnaíba, possui aspectos similares nas características observadas, e em divergência com o cluster 1 . Principalmente nos valores extremamente inferiores de total de recurso captado (cerca de 120 vezes menor que o cluster 1 e 45 vezes menor que o cluster 3 ), e inferiores em quantidade de projetos aprovados e quantidade de projetos finalizados.

O cluster 3, composto pelos municípios de Carapicuíba e Itapevi apresenta maior similaridade nos valores captados, no total de projetos aprovados e no total de projetos cancelados, diferencia-se dos demais por possuir resultados em 
sua maioria medianos quando comparado aos demais, com um total de recurso captado cerca de 2,6 vezes inferior ao do cluster 1 e 45 vezes superior ao cluster 2, bem como quantidade de projetos aprovados e quantidade de projetos finalizados em valores significativamente superiores ao cluster 2 e inferiores ao cluster 1.

O Quadro 11 apresenta a distância entre centros do cluster finais. Percebe-se que o cluster 1 e o cluster 2 são os que apresentam maior distância entre si, de 349.441.060,844.

\section{Considerações finais}

Este estudo teve o objetivo de analisar a captação de recursos federais, via transferências voluntárias, realizada por municípios que compõem o Consórcio Público Intermunicipal da Região Oeste Metropolitana de São Paulo (Cioeste).

Embora seja prematuro avaliar a efetividade do Cioeste, tendo em vista sua recente criação (novembro/2013), de maneira geral observa-se que a escolha pelo consorciamento é justificada, uma vez que se revela uma alternativa a que se socorrem os municípios brasileiros objetivando estimular sistemas cooperativos e o desenvolvimento regional.

A formação de Consórcios Públicos Intermunicipais vem somando esforços - e contrapartidas - para projetos de benefício regional. Apesar desse esforço para o desenvolvimento, alguns municípios do Cioeste apresentam perfil socioeconômico e comportamento de captação de recursos distintos, o que requer maior atenção da instituição, a fim de melhorar a eficiência, o desempenho e a qualidade dos projetos em âmbito municipal e regional.

Nesse sentido, a pesquisa apontou que, em que pese o município de Barueri ter revelado pior resultado em captação de recursos federais para execução de projetos de interesse público, não significa que o município não o faça com outras fontes. Isso porque se observa que a receita corrente desse município é superior à do município de Osasco e, se for analisada a receita corrente per capita, esse valor é ainda mais significativo.

Sendo assim, é possível aferir a hipótese de que Barueri faz investimentos internos apenas com recursos municipais, isso porque todas as outras variáveis sociais e econômicas possuem bom desempenho. Por outro lado, devido a suas características econômicas e em razão da não adesão às transferências financeiras condicionadas, torna-se menos dependente de normas e condicionalidades de programas do Governo Federal.

Da mesma forma, em proporções bem inferiores, verificamos que Santana de Parnaíba também possui bom desempenho nos indicadores socioeconômicos e 
também não teve uma captação de recursos expressiva.

Com exceção de Osasco, os demais municípios apresentaram padrão de baixa captação de recursos, o que justifica a necessidade do consorciamento regional para ampliação de fontes de financiamento e maior equidade na captação de recursos frente às demandas sociais.

Desde a reabertura democrática e o processo de descentralização das políticas públicas, os municípios brasileiros passaram a identificar a necessidade de planejar, de organizar e operacionalizar a gestão pública a fim de melhorar a eficiência, o desempenho e a qualidade dos projetos em âmbito municipal, o que demonstrou a necessidade tanto de criação de uma equipe específica para lidar com o planejamento e gestão das políticas públicas, em especial os escritórios de projetos, quanto de criação de bancos de projetos, os quais devem ser a base para o planejamento dos municípios, permitindo ser possível a continuidade dos planos traçados mesmo em casos de alteração da gestão.

Garantir representatividade, no caso, do Cioeste, junto aos órgãos financiadores, em especial com o Governo Federal, é outro elemento essencial para garantir a captação de recursos para o âmbito regional, isso porque muitos projetos são negociados por seus representantes e repassados aos municípios interessados por meio de emendas parlamentares, contratos de repasse ou convênios diretos com os órgãos concedentes.

Assim sendo, recomenda-se que em pesquisas futuras sejam abordadas variáveis quanto à influência do partido dos prefeitos e/ou coligações nas respectivas gestões e, bem assim, o presidente da República da ocasião, visando avaliar se essas influências foram ou não determinantes para a captação de recursos federais. Isso poderia explicar a elevada captação de recursos pelo município de Osasco.

Segundo Marta Farah (2001), "a articulação entre governos municipais e entre diferentes esferas de governo assinala a possibilidade de estabelecimento de um novo tipo de vínculo intergovernamental", distinto do clientelismo e da condição dos municípios de simples executores de políticas públicas federais. "Neste novo vínculo - de parceria - há uma co-responsabilização pela política e seus resultados, ainda que a cada um dos participantes possam caber papéis diferenciados ao longo do processo de implementação das políticas" (FARAH, 2001, p. 136).

Por todo o exposto, o consorciamento tem sua importância no sentido de aumentar a cooperação entre os municípios, colocar em pauta problemas e demandas regionais e garantir maior representatividade junto às esferas de governo e à iniciativa privada, possibilitando soluções e melhores resultados para os cidadãos. 


\section{Referências bibliográficas}

ABRUCIO, Fernando Luiz. Trajetória recente da gestão pública brasileira: um balanço crítico e a renovação da agenda de reformas. Rev. Adm. Pública, Rio de Janeiro, v. 41, n. spe, p. 67-86, 2007.

AlmeIdA, Maria Hermínia Tavares de. Recentralizando a Federação? Revista de Sociologia e Política: Dossiê Federalismo, Universidade Federal do Paraná, n. 24, junho 2005.

Alvares, M. A. A. et al. Projetos executados com recursos externos em Osasco: diagnóstico e soluções. In: Alexandre Guerra et al. (Org.). Planejamento público e gestão por resultados: uma experiência municipal aplicada. São Paulo: Hucitec, 2016. v. 1, p. 82-101.

BRASIL. Lei no 11.107, de 6 de abril de 2005. Dispõe sobre normas gerais de contratação de consórcios públicos e dá outras providências. Disponível em: < http://www.planalto.gov.br/ccivil_03/_Ato2004-2006/2005/Lei/L11107.htm>. Acesso em: 13 ago. 2016.

BRANCO, Marcello Simão. O federalismo em conceitos e na realidade brasileira. In: DANTAS, Humberto; MARTINS JÚNIOR, José Paulo. Introdução à política brasileira. São Paulo: Editora Paulus, 2007. p. 109-124.

COTIA AgorA. Disponível em: <http://www.jornalcotiaagora.com.br/prefeitos-docioeste-ampliam-dialogo-com-legislativo-da-regiao-oeste/>. Acesso em: 08 ago. 2016.

FARAH, Marta Ferreira Santos. Parcerias, novos arranjos institucionais e políticas públicas no nível local de governo. Revista Brasileira de Administração Pública, Rio de Janeiro, v. 35, n. 1, p. 119-144, 2001.

Ferreira, F. Whitaker. Planejamento sim e não: um modo de agir num mundo em permanente mudança. Rio de Janeiro: Paz e Terra, 1979.

FRANZeSE, Cibele. Federalismo cooperativo no Brasil: da Constituição de 1988 aos sistemas de políticas públicas. São Paulo, tese de doutorado, Escola de Administração de Empresas de São Paulo, Fundação Getúlio Vargas, 2010.

GUIDINI, M. B. et al. Aplicação do K-Means Cluster para classificação de estilos gerenciais. In: Encontro NACIONAL DE ENGENhARIA DE PRODUção, 28., 2008, Rio de Janeiro. Anais... Rio de Janeiro, 2008.

Governo de Minas Gerais. Cartilha do Choque de Gestão Municipal. Disponível em: <http://www.conversandosobregestao.mg.gov.br/documentacao/conteudo/ cartilhas/cartilha_captacao_de_recursos.pdf>. Acesso em: 15 ago. 2016.

InStituto BRAsileiro de GeOgRafia e Estatística (IBGE). Disponível em: <http:// www.cidades.ibge.gov.br/xtras/home.php>. Acesso em: 08 de ago. 2016.

MAchado, José Angelo; PALOtTI, Pedro Lucas de Moura. Entre cooperação e centralização: federalismo e políticas sociais no Brasil pós-1988. Revista Brasileira de Ciências Sociais, v.30, n. 88, p. 61-83, 2015.

Meu Municípıo. Disponível em: <https://meumunicipio.org.br/>. Acesso em: 03 ago. 2016. 
ORTIZ, M. S. P.; MEDEIROS, A. K.. Reforma gerencial na gestão pública contemporânea: desafio para os municípios brasileiros. In: CONGRESSO CONSAD DE GESTÃo PúBLICA, 8., 2015, Brasília. Anais... Brasília: Consad, 2015.

OSASCO. Lei no 4611, de 12 de novembro de 2013. Ratifica o protocolo de intenções firmado entre os municípios integrantes do Consórcio Intermunicipal da Região Oeste Metropolitana de São Paulo - Cioeste. Disponível em: <http://leismunicipa. is/ilgqr>. Acesso em: 15 ago. 2016.

PACHECO, Regina Silvia. Contratualização de resultados no setor público: a experiência brasileira e o debate internacional. In: CONGRESO INTERNACIONAL DEL CLAD SOBRE LA Reforma del ESTAdo Y DE LA AdMinistración PúblicA, 9., 2004, Madrid. Anais... Madrid: Clad, 2004.

PIRES, V. et al. Dossiê - Campo de públicas no Brasil: definição, movimento constitutivo e desafios atuais. Administração Pública e Gestão Social, v. 6, n. 3, p. 110-126, 2014.

Portal da Transparência. Dados de Transferências Voluntárias. Disponível em: <http://www3.transparencia.gov.br/TransparenciaPublica/>. Acesso em: 19 jul. 2016.

Portal da TRAnSPARÊnCIA. Classificação das Transferências. Disponível em: <http:// www. portaltransparencia.gov.br/glossario/DetalheGlossario.asp?letra=t>. Acesso em: 08 ago. 2016.

PRADo, Darci. Gerenciamento de projetos nas organizações. 2. ed. Belo Horizonte: EDG, 2000.

PRATES, Ângelo. Os consórcios públicos municipais no Brasil e a experiência européia: alguns apontamentos para o desenvolvimento local. In: CONGRESSO CONSAD DE GeStÃo PúblicA, 3., 2010, Brasília. Anais... Brasília: Consad, 2010.

Rabelo, Gabriela; Alvares, Merlyn A.; SAntos, Valderez M. Resultados e desafios na implementação do gerenciamento, monitoramento e avaliação de projetos prioritários da Prefeitura de Osasco/SP. In: CONGRESSO DE GESTÃo E POLÍTICA PúBLICA - EPPEN/UnifESP, 1., 2015, Osasco. Anais eletrônicos... Osasco: Eppen/Unifesp, 2015. Disponível em: <http://www.seplag.osasco.sp.gov.br/Publicacao>. Acesso em: 15 jul. 2016.

Senado Federal. Manual de Obtenção de Recursos Federais para Municípios. Disponível em: <http://www.senado.gov.br/senadores/Senador/psimon/livros/ livro030.pdf>. Acesso em: 15 ago. 2016.

SERPRO. Disponível em: <https://www.serpro.gov.br/linhas-negocio/catalogo-desolucoes/solucoes/principais-solucoes/siconv-sistema-de-convenios>. Acesso em: 08 ago. 2016.

Silva, Vilma B.; MedeIRos, Anny K. Regras universais e realidades locais - gestão das transferências voluntárias em Osasco/SP. In: CONGRESSO DE GESTÃo E POLÍTICA PúBliCA - EPPEN/UnifeSP, 1., 2015, Osasco. Anais eletrônicos... Osasco: Eppen/ Unifesp, 2015. Disponível em: <http://www.seplag.osasco.sp.gov.br/Publicacao>. Acesso em: 15 jul. 2016. 


\section{Merlyn Alvares Ambrosio Alvares}

Possui mestrado em Gestão de Políticas e Organizações Públicas pela Universidade Federal de São Paulo (Unifesp). Contato: merlynalvares@gmail.com

\section{Marcello Simão Branco}

Possui doutorado em Ciência Política pela Universidade de São Paulo (USP). Atualmente é professor do Departamento Multidisciplinar da Universidade Federal de São Paulo (Unifesp), campus de Osasco. Contato: marcellobranco@ig.com.br 